\title{
Attitude toward and application of off-pump coronary artery bypass after continuing education retraining
}

Richard J. Novick, MD, and Michael W. Chu, MD

See related article on page 154.

From the Department of Cardiac Surgery London Health Science Center, London, Ontario, Canada.

Received for publication Aug 22, 2005; accepted for publication Aug 29, 2005.

Address for reprints: Richard J. Novick, MD, Division of Cardiac Surgery, London Health Sciences Centre, University Hospital 339 Windermere Road, London, ON N6A 5A5, Canada (E-mail: richard.novick@lhsc.on.ca).

J Thorac Cardiovasc Surg 2006;131:14-5

$0022-5223 / \$ 32.00$

Copyright () 2006 by The American Association for Thoracic Surgery

doi:10.1016/j.jtcvs.2005.08.054
$\mathrm{T}$ he objective of this provocative article by Albert and associates ${ }^{1}$ was to study the impact of a 2-day, multimodal, continuing medical education and retraining course on the subsequent attitude toward, application of, and "complexity score" of off-pump coronary artery bypass grafting (OPCAB). The authors of this paper reengineered their institution toward OPCAB for all patients and all surgeons 6 years ago and had extensive prior experience in providing multimodal individual training to surgeon and anesthesia teams for this procedure. In addition, Dr Sargeant's team has a venerable track record in coronary artery bypass outcome analysis. The prospective benefits of OPCAB for all patients remain controversial, and our recent meta-analysis of randomized controlled trials showed no significant reduction in mortality, stroke, or perioperative myocardial infarction rates with OPCAB as compared with conventional on-pump coronary artery bypass. ${ }^{2}$ Nonetheless, secondary outcomes such as postoperative ventilation time, atrial fibrillation rates, and intensive care unit and hospital lengths of stay were significantly reduced after the former procedure. Research at our center has also shown that the transition from routine on-pump coronary artery bypass to OPCAB can be accomplished safely, ${ }^{3}$ even without the multimodal surgical team training described by the authors of this article. Despite these findings, the undeniable fact is that the projected wide dissemination of OPCAB has stalled and the majority of cardiac surgeons remain unconvinced as to whether the increased personal stress associated with OPCAB procedures pays sufficient dividends in patient outcomes to mandate a widespread change in practice. Accordingly, many cardiac surgeons reserve OPCAB for elderly, high-risk patients with multiple comorbidities, in whom at least one recent randomized controlled trial has shown a significant benefit. ${ }^{4}$

Albert and colleagues are to be congratulated for their tenacity in assessing the initial and 3-month impact of their educational program on OPCAB attitudes and application. Figure 1, which showed the most frequently cited "complexity criteria" at training entry, exit, and after 3 months, was beautifully illustrated and showed most clearly the impact that the authors' educational program had on attitudes toward OPCAB. However, we found some of the data analysis in this article to be difficult to fully understand. In the Discussion section, the authors indicated that they attempted to create a "control group" and to document indirect information about $\mathrm{OPCAB}$ attitudes and practice among nonvisiting members of the team. Ideally, attitudes toward OPCAB and the application of this procedure in subjects who underwent the educational program and the control group surgeons who did not should have been presented in tabular format side by side; however, the only element of data presented on the control group was that their OPCAB application rate changed from $8.2 \%$ to $10.3 \%$ during a 3-month interval. Even if these two groups could have been compared, it would have been difficult to interpret the results because of significant bias within the intervention group. Perhaps it would have been better to compare the intervention group with a group experiencing another OPCAB learning modality, such as didactic presentations alone, selflearning guides, high-fidelity simulators, or pure intraoperative guidance. We were also perplexed by the results of Table 2, which indicated that attending an OPCAB live demonstration (but not a large-audience OPCAB educational program) before the 2-day course had an independent negative impact on the OPCAB rate of the surgeons 3 months after training. Albert and colleagues correctly noted that with 
only 50 surgical-anesthetic teams participating in this study the ability to perform proper multivariable logistic regression analyses was limited.

This study used multiple educational modalities to enhance the "transfer" of OPCAB knowledge and skills. It is likely that some modalities were more successful than others, and for future courses offered at Leuven Continuing Medical Education of Surgical Technologies it would be useful to establish the efficacy of each modality, to identify those with highest value. In regard to procedural skills development, low-fidelity models have been used successfully for junior surgical residents who are learning simple, purely technical tasks (authors' reference 24). The rationale to continue using low-fidelity models is that they are inexpensive and reproducible. Performing OPCAB surgery successfully, however, requires the acquisition of a complex set of knowledge, decision-making, and procedural-based skills to function optimally within a team environment. We believe that this cannot be accurately simulated by a lowfidelity model and therefore high-fidelity models or intraoperative mentorship in OPCAB should be sought. Ultimately, the development of expertise in any field requires a large amount of practice, approximately 10,000 hours within one specific domain. ${ }^{5}$ Although all of the course participants will arrive with different levels of comfort with $\mathrm{OPCAB}$, as adult learners, the point must be emphasized that practice is most effective when it is deliberate and most realistic. Efforts to improve OPCAB learning should ideally evolve from this principle.

Like every good study, this one raised more questions than it answered. The authors noted a significant erosion in attitudes about OPCAB at the 3-month mark after their course, as clearly depicted in their Figure 1. Furthermore, only $64 \%$ of surgeons considered OPCAB beneficial for all patients at 3 months, versus $90 \%$ immediately after the course. Why did the enthusiasm for OPCAB wane? The fact that the OPCAB application rate of the trained surgeons increased by an absolute value of $26 \% 3$ months after the course is commendable, but demonstrates the difficulty of sustaining a change in surgical practice, especially if one's surgical and anesthesiology colleagues and the department leadership are not on board. It would be fascinating to document the attitude toward OPCAB and its actual application in the intermediate term (eg, 1 year) after the course in study participants, although the authors indicated that it was very labor intensive to obtain complete 3-month follow-up in their study. Should one expect a further erosion of attitudes toward OPCAB by the 1-year mark? It is highly likely that if the application of OPCAB is to be sustained and a significant "coat tail effect" is to be exerted on one's peers, forward-looking leadership to maintain a fundamental change in practice is mandatory. Only then will full "buy in" of the results of this educational program be achieved in the institutions of participating surgical teams.

\section{References}

1. Albert A, Peck EA, Wouters P, Van Hemelrijck J, Bert C, Sergeant P. Performance analysis of interactive multimodal continuing medical education retraining on attitude toward and application of off-pump coronary artery bypass. J Thorac Cardiovasc Surg. 2006;131:154-62.

2. Cheng DC, Bainbridge D, Martin JE, Novick RJ. Does off-pump coronary artery bypass reduce mortality, morbidity and resource utilization when compared to conventional coronary artery bypass? A meta-analysis of randomized trials. Anesthesiology. 2005;102:188-203.

3. Novick RJ, Fox SA, Stitt LW, Swinamer SA, Lehnhardt KR, Rayman $\mathrm{R}$, et al. Cumulative sum failure analysis of a policy change from on pump to off pump coronary artery bypass grafting. Ann Thorac Surg. 2001;72:S1016-21.

4. Carrier M, Perrault LP, Jeanmart H, Martineau R, Cartier R, Page P. Randomized trial comparing off-pump to on-pump coronary artery bypass grafting in high-risk patients. Heart Surg Forum. 2003;6:E8992.

5. Ericsson KA, Charness N. Expert performance: its structure and acquisition. Am Psychol. 1994;49:725-47. 